\title{
A DISSOLUÇÃO E A REINVENÇÃO DO SENTIDO DE COMUNIDADE EM BEUNINGEN, HOLANDA*
}

\section{Heitor Frúgoli Jr.}

O presente artigo discute os supostos da "dissolução da comunidade" e da "ausência de uma identidade mais clara" entre os moradores da aldeia de Beuningen, próxima à cidade de Nijmegen, ao leste da Holanda. Essas hipóteses, anteriores à minha chegada, estavam expressas no

* Trabalho apresentado na XXIII Reunião Brasileira de Antropologia, no fórum de pesquisa "Cidades, representações e experiência social", em Gramado, jun. 2002, e no XXVI Encontro Anual da Anpocs, no grupo de trabalho "Cidade, metropolização e governança urbana”, em Caxambu, out. 2002. Agradeço a Hans Venhuizen, Maureen Timmermans, Piet Snelaars, Paul Meurs, John Spindler, Selmo Norte, Sonia Kane, Cleisa Rosa e a todos os entrevistados. Sou também grato aos valiosos comentários de Geert Banck e Tony Robben e dos colegas quando da apresentação deste estudo.

Artigo recebido em novembro/2002. Aprovado em maio/2003. diagnóstico de um projeto sobre Beuningen: ${ }^{1}$ tratava-se de uma região em processo de transição, o que tornava problemática sua caracterização como uma área rural ou urbana, e que vinha passando por uma diversificação de grupos sociais dos antigos fazendeiros locais aos moradores mais recentes (em geral, da alta classe média), além de pequenos empresários e habitantes mais antigos (de menor poder aquisitivo) -, configurando, segundo o projeto, uma "cultura não uniforme”, com diferenças quanto às trajetórias empregatícias e residenciais, às atitudes diante da vida e até quanto aos hábitos alimentares. Um dos desafios, portanto, era compreender melhor tal dinâmica social, visando à formulação de novos estímulos para uma "continuidade cultural" no local, por meio da criação dos elos e conexões possíveis entre esses diferentes grupos (cf. Venhuizen e Timmermans, 2000). A idéia de que Beuningen estava se tornado uma "cidade dormi- 
tório"2 - sobretudo com a chegada cada vez mais intensa de novos moradores que trabalham em outras cidades, principalmente Nijmegen - devia ser investigada no sentido de descobrir sua "nova identidade". Parte desse diagnóstico, bem como certos objetivos do próprio projeto a partir do qual se originou esta reflexão serão discutidos ao longo deste artigo, com base na minha pesquisa de campo no local. ${ }^{3}$

\section{Referências teóricas}

Antes de entrarmos nos dados etnográficos propriamente ditos, é necessário situar algumas referências conceituais, sobretudo quanto ao tema da comunidade - presente não apenas no projeto, mas recorrente em vários depoimentos -, já que tal conceito envolve múltiplos sentidos e as críticas quanto ao seu uso em pesquisas já são de longa data. Como se trata de uma discussão ampla, cabe situar apenas os tópicos essenciais, centrados a princípio no contraponto entre comunidade e sociedade e, de forma correlata, entre campo e cidade.

Desde ao menos os meados do século XIX, época da emergência da sociedade moderna, ${ }^{4}$ urbana e industrial, o tema da comunidade constitui uma espécie de contraponto societário à modernização. Já na reflexão sociológica dessa fase, vários autores analisavam a comunidade sob uma tipologia social marcada em geral por grupos de pequena escala, que estabeleceriam relações solidárias, coesas, pessoais, espontâneas, cotidianas e permanentes, em que se configurariam certas identidades comuns - com a consciência ou sentimento do "nós", em oposição aos "outros" - propícias à prática da "vida em comum" e do associativismo. ${ }^{5}$

Esse quadro, baseado numa espécie de "narrativa da perda”, permitia pensar, por oposição, as várias faces do mundo moderno em constituição, assinalado por novas formas de organização social em que vinham predominando as relações formais e de interesse, os acordos contratuais, a lógica do mercado, a competição individual e as multidões urbanas e anônimas (cf. Fernandes, 1973).
Assim como a noção de comunidade se revestiu de aspectos idealizados de um passado de certa forma inexistente, o campo também acabou por assumir sentidos correlatos, numa espécie de recuo imaginário e por vezes bastante conservador - como mostra Raymond Williams no caso da literatura inglesa da passagem do século XIX para O XX -, a uma vida supostamente mais pacífica, inocente e virtuosa, ante um contexto de mudanças aceleradas, marcado pela "tensão de uma sociedade cada vez mais intrincada e interdependente" (cf. Williams, 1989 [1973], pp. 11 e 341). Boa parte do imaginário da época sobre as cidades remetia-se então ao vício, à decadência, às massas anônimas, cujo temor reforçava por vezes críticas arcaizantes, que pregavam o retorno ao campo ou a pequenas cidades (cf. Schorske, 2000, pp. 53-72).

Dessa forma, a tensão entre comunidade como reconstrução simbólica de um suposto passado perdido - e sociedade moderna tem de certa forma se mantido recorrente até o presente, obviamente sob distintas sínteses e ressignificações, tanto no campo das representações sociais, como nas formas concretas com que certos grupos sociais buscam se situar e se organizar dentro da cidade. Ou seja, a noção de comunidade persiste como uma espécie de referência simbólica - desejada ou imaginada -, mas é preciso também enfocá-la como uma estratégia discursiva articulada a determinadas práticas concretas, vinculadas, por sua vez, a objetivos políticos, por vezes difusos, em outros casos, bastante definidos. Isso se dá por razões distintas e muitas vezes envolve grupos marginalizados e de menor poder aquisitivo como, por exemplo, migrantes que tentam recriar comunidades marcadas pela origem comum, ou favelados que tentam se organizar comunitariamente, na luta pela obtenção de equipamentos urbanos coletivos (cf. Durham, 1973; Kowarick, 2000; Banck, 1998). Mas isso também tem norteado, com dinâmicas peculiares e distintas, a busca, por parte de grupos de maior poder aquisitivo, de espécies de comunidades em torno de moradias nas "bordas" das cidades modernas, ou mesmo em espaços seletivos e auto-segregados no interior da própria cidade. 
Tendo em vista esse último caso, é importante ressaltar, com um pequeno recuo histórico, a procura, no plano citadino, de espaços ao mesmo tempo urbanos, mas a salvo de seus "males". Já no final do século XVIII tivemos na Inglaterra o desenvolvimento das country villas, primeiramente nos arredores de Londres, voltadas às classes sociais de maior poder aquisitivo e identificadas por um certo "estilo de vida" - gentlemanly manner - à busca de um "retiro" numa segunda residência, mais próxima da atmosfera "romântica" do campo. Já no início do século XX, pode-se mencionar as primeiras garden cities inglesas, em que grandes empresas imobiliárias assumiram a construção e a administração de verdadeiros bairros suburbanos planejados, com casas situadas em ruas sinuosas que cortavam áreas bastante arborizadas (cf. Girouard, 1985, pp. 277-284 e 351353; Marins, 1998, pp. 180-187).?

Já nos Estados Unidos, criaram-se ao longo do século XX os subúrbios, em que uma grande parcela das classes médias brancas passou a habitar para fugir das áreas mais centrais - marcadas cada vez mais pela concentração de "problemas urbanos" (no caso, concentrações étnicas, violência e deterioração) -, em busca da casa própria em bairros apenas residenciais, com pequena densidade populacional, em áreas distantes do trabalho - conectadas diariamente graças ao automóvel -, o que resultou em vastos espaços que esgarçaram as fronteiras urbanas, sem vida pública significativa, segregados em termos de renda, etnia e estilo de vida (cf. Jackson, 1985).

Para além dessa complexidade, os desdobramentos contemporâneos desse fenômeno abrem novas questões também desafiantes. A dinâmica metropolitana mais recente tem acarretado o deslocamento de grupos de razoável poder aquisitivo para distintos tipos de áreas de moradia nas "franjas urbanas", com destaque para as gated communities, presentes em cidades como Los Angeles, São Paulo ou Johannesburgo, marcadas em geral por fortes sistemas de isolamento, proteção e vigilância, decorrentes, de um modo geral, de uma proximidade geográfica tensa entre classes sociais e etnias diferenciadas, num contexto marcado por altos índices de violência urbana (cf.
Davis, 1990; Caldeira, 2000; Landman, 2000). Isso entretanto não se aplica com precisão ao presente caso, pois em Beuningen e, de um modo geral, em outras cidades holandesas, os grupos sociais mais privilegiados não formam espaços isolados por rígidos sistemas de segurança, uma vez que não há no país um contexto de desigualdades sociais tão flagrantes, além de índices bem menores de ocorrências violentas, apesar de crescentes (cf. The Economist, 2002).

Em muitos desses novos empreendimentos, deve-se frisar como o próprio mercado imobiliário tem explorado e mesmo forjado uma idéia positiva da "vida em comunidade" aos moradores, incorporando tal tema como estratégia de marketing. Ainda que essa prática não seja recente, já que se faz presente ao menos desde certos projetos de garden cities (cf. Girouard, 1985, p. 352), é importante compreender como ela assume novas formas ao longo do desenvolvimento urbano. É o caso das atuais edge cities ("cidades de contorno") dos Estados Unidos, que, dada a proliferação de empregos do setor terciário moderno nas próprias áreas suburbanas - como ocorre no sul da Califórnia -, fixa os habitantes nesses locais, na dupla condição de moradores e trabalhadores, e incentiva-os a se organizar comunitariamente para a resolução de seus problemas, reforçando assim o caráter associativo presente na sociedade norte-americana (cf. Garreau, 1991). Tais fenômenos têm acentuado a separação desses espaços para com o resto da cidade, incluindo os movimentos de "desanexação urbana", no qual os moradores vêm se organizando, utilizando instrumentos democráticos, mas afim de se autonomizar e de acentuar a diferenciação e a exclusividade desses territórios com relação aos arredores (cf. Holston e Appadurai, 1996).

Se as oposições costumeiras entre comunidade e sociedade devem ser alvo de problematização, de modo correlato deve-se atentar aos contrapontos aparentemente simples entre o rural e o urbano, tendo em vista a dificuldade recorrente em separar de forma nítida ambos os planos, como a que foi enfrentada em certos momentos da presente pesquisa. Como abordarei adiante, a Escola de Chicago estabeleceu a partir dos anos de 1920 um claro contraste entre campo e cidade, 
introduzindo o estudo da cultura urbana como algo totalmente distinto dos hábitos e heranças rurais, o que influenciou muitos estudos a partir de então. Os cruzamentos entre campo e cidade, entretanto, supõem inúmeras sínteses, pois se até aqui focalizamos sobretudo fenômenos de absorção do "campo" pela "cidade", em outros contextos pode ocorrer justamente o contrário, como mostra Canclini quanto a vários processos ocorridos na África, na Ásia e na América Latina - em que se costuma dizer que "as cidades foram invadidas pelo campo" -, resultando em pontos de interseção entre o urbano e o rural que não podem ser entendidos em termos de simples oposição (Canclini, 1997, pp. 349-350). Pensando no cenário brasileiro, ${ }^{8}$ um contexto evidentemente distinto da presente pesquisa, regiões situadas na fronteira entre o campo e uma urbanização precária, como em São Paulo, já chegaram a ser chamadas, na passagem dos anos de 1970 para os de 1980, de áreas "rurbanas".

Na França, o termo rurbanisation tem assumido um sentido, ao contrário dos casos acima, de "invasão da cidade pelo campo", dada uma nova busca, a partir dos anos de 1970, de um "estilo de vida" mais próximo da "atmosfera rural" por parte de setores médios e superiores, novamente promovido por grandes empresas imobiliárias. De toda forma, tendo em vista o crescente entrelaçamento entre o rural e o urbano - em virtude da forte presença em ambos de sistemas de produção e distribuição, do setor terciário e das modernas formas de comunicação -, prefere-se neste contexto falar, em geral, de uma hegemonia urbana, em vez da antiga dicotomia rural-urbano (cf. Raulin, 2001, pp. 69-72). ${ }^{9}$

Cabe ainda abordar um tema não menos complexo, relativo aos estudos de comunidade, embora não se pretenda fazer no espaço restrito deste ensaio um balanço dessa produção. Parte da reflexão da antropologia urbana tem sido marcada pela preponderância da contraposição entre campo e cidade, desde a formulação do continuum folk-urbano, a partir do estudo etnográfico de Robert Redfield sobre a aldeia mexicana de Tepoztlán (cf. 1974 [1930]), tendo recebido maior profundidade teórica em abordagens posteriores (cf. Redfield 1947, 1953, 1955). Em linhas gerais, uma sociedade do tipo folk constituiria para Redfield uma típica "comunidade", marcada, de modo geral, por um relativo isolamento, divisão de trabalho pouco desenvolvida - com um conjunto razoável de atividades comunais -, pequena mobilidade tanto física como social e preponderância da dimensão sagrada e religiosa (cf. Hannerz, 1980, pp. 60-61). Isso contrastaria, por sua vez, com o universo urbano delineado por Louis Wirth, também da Escola de Chicago, no qual as marcas predominantes seriam a heterogeneidade de grupos sociais, a densidade de interações sociais, o predomínio crescente de relações formais e burocráticas, um maior isolamento individual, a nuclearização da família e a secularização (cf. Wirth, 1987 [1938]; Hannerz, 1980; Oliven, 1985).

Como se sabe, os trabalhos de Oscar Lewis (1951 e 1965) criticaram de maneira contundente o continuum folk-urbano e a todas as suas decorrências, abrindo com isso novas perspectivas na antropologia urbana. Sua etnografia, realizada dezessete anos depois na mesma Tepoztlán, contrapôs-se à idéia de uma comunidade homogênea, isolada e suficientemente integrada, ao dar visibilidade a vários conflitos internos - ligados, entre outros, à prática política e à posse da terra - além de admitir mudanças em curso, embora não necessariamente vinculadas à urbanização. Nesse sentido, a idéia de uma mudança cultural progressiva do pólo do campo para o da cidade deveria ser substituída pela noção de uma crescente ou decrescente heterogeneidade dos elementos culturais inerentes à própria comunidade, evitando-se assim um approach evolucionista, ainda que numa crítica marcada por outros limites inerentes ao enfoque culturalista. Mesmo a idéia de contatos primários e pessoais, que predominariam na cultura folk, poderiam ser contrapostos por um razoável grau de formalismo e impessoalidade, antes creditados por Redfield e Wirth principalmente ao contexto da "cultura urbana" (cf. Hannerz, 1980). ${ }^{10}$

Apesar dessas críticas, vários estudos de comunidade posteriores padeceram de novos problemas, advindos sobretudo de uma perspectiva culturalista ainda problemática. Mesmo tendo au- 
xiliado a definir contextos etnográficos mais precisos e a propiciar abordagens mais sistemáticas, baseadas em pesquisas de campo detalhadas que ampliaram o conhecimento sobre tais realidades sociais, muitos estudos de comunidade carecem de uma articulação mais consistente entre o contexto pesquisado e a totalidade social mais ampla, além de não contemplarem claramente os temas da mudança social e dos conflitos (cf, Woortmann, s. d.). Como aponta Woortmann, uma das superações desses impasses residiria em definir problemas mais claros, em vez da busca incerta de um isolado empírico articulado internamente por uma suposta totalidade integrada (Idem, p. 112). Para além dos problemas apontados, sobretudo quanto à posição funcionalista não só da "integração das partes no todo", mas também da "presença da totalidade nas partes", que obscurecem uma compreensão plena da relação dos contextos estudados com a realidade mais ampla, Durham também alerta para a falta de uma problematização mais delineada nos estudos de comunidade no que diz respeito à relação entre sujeito e objeto, com a produção de um conhecimento bastante colado às "representações nativas". Isso, entretanto, levou a que determinados estudos antropológicos posteriores construíssem, por assim dizer, abordagens etnográficas ainda inspiradas no funcionalismo, mas com interpretações de cunho marxista - dada inclusive a crescente politização dos grupos pesquisados -, com a utilização de conceitos apenas alusivos numa perspectiva muito marcada por "deslizes semânticos" (cf. Durham, 1986), que gerou novos problemas para a disciplina.

É oportuno mencionar, nesse sentido, a importância da obra Os estabelecidos e os outsiders, de Elias e Scotson (2000 [1965]), estudo de uma pequena cidade no interior da Inglaterra na passagem dos anos de 1950 para os de 1960, relativamente homogênea - sem nítidas diferenças de classe social, inserção profissional ou origem étnica -, mas com uma configuração de poder que delimitava uma forte separação entre dois grupos os "antigos" (moradores a partir das décadas de 1920 e 1930) e os "novos" (inicialmente imigrantes que ocuparam uma nova área a partir dos anos de 1930 e, depois, vários desabrigados da Segunda Guerra Mundial). Essa demarcação baseou-se em critérios de tempo de moradia e de inserção nas redes tradicionais de solidariedade, que fundamentavam uma hierarquia classificatória excludente para com os moradores mais recentes - os "forasteiros" -, estigmatizados de várias formas. Tal abordagem mostra como certos tipos de integração comunitária se articulam diretamente com formas específicas de coerção e opressão, ou seja, há aqui uma originalidade ao se estabelecer nexos entre certos fundamentos simbólicos da formação de um senso de comunidade ou de pertencimento com estratégicas políticas de dominação de um grupo "coeso" sobre outros grupos "menos coesos", com uma clara "configuração de poder".

No caso de Beuningen, ainda que em circunstâncias muito distintas, ocorre também uma espécie de conflito, mais brando e menos explícito, entre os moradores mais velhos e os mais recentes, ainda que sejam os últimos que detenham, nesse contexto, maior poder aquisitivo e estejam mais organizados coletivamente. Isso tem levado a embates que no plano discursivo remetem, no caso dos antigos moradores, a uma dimensão utópica situada num passado em que realmente teria existido uma "coesão comunitária, cooperativa e solidária”, em parte perdida devido à chegada dos novos habitantes; esses últimos, entretanto, estão mais "coesos" e organizam-se de forma bastante pragmática, também acionando a existência de uma (nova) comunidade, voltada à obtenção de recursos e benefícios que atendem a interesses bastante particulares e que impõem uma perda à aldeia como um todo, ou seja, uma comunidade muito fundada numa diferença que se acentua com relação aos demais grupos locais, como se verá a seguir.

\section{Estudo de caso: Beuningen, Holanda}

\section{Consolidação da urbanização e mercado imobiliário: os novos moradores}

Há vinte anos atrás, a população das quatro aldeias da região, situadas a oeste de Nijmegen - 
Weurt, Beuningen, Ewijk e Winssen (que juntas formam o município de Beuningen) -, era de aproximadamente 16 mil habitantes, com uma média de 5 pessoas por casa e cerca de 200 fazendeiros, numa área ainda basicamente agrícola. Hoje essa população saltou para 26 mil (num crescimento acima de 60\% em duas décadas), com uma média de 2,5 moradores por casa (as moradias aumentaram em $225 \%$ no mesmo período) e uma redução para apenas cinqüenta fazendeiros ( $25 \%$ do número anterior), que enfrentam sucessivas crises e são cada vez mais dependentes de subsídios governamentais). ${ }^{11}$ Configura-se, também em termos demográficos, uma área em transição para um contexto urbano ou, em outras palavras, para uma determinada hegemonia urbana.

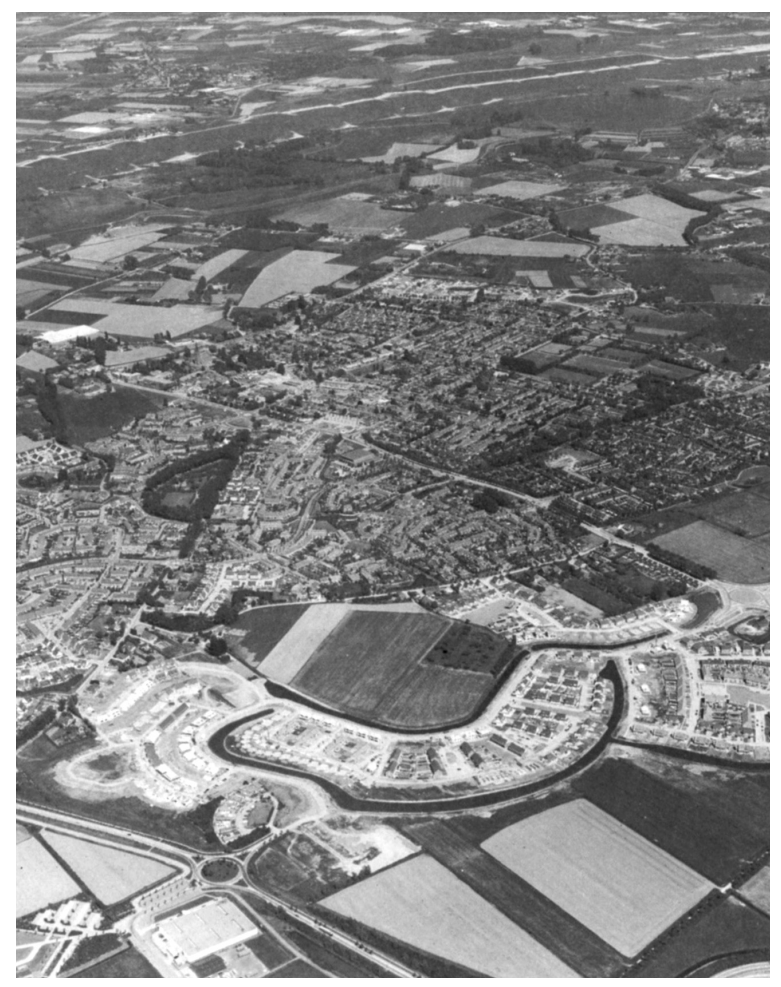

Vista aérea da aldeia de Beuningen, com o condomínio Beuningse Plas no primeiro plano e o Rio Waal ao fundo (foto extraída de Beeldkwaliteitsplan Gemeente Beuningen, 1995, p. 5).

A aldeia de Beuningen vem sendo a principal responsável por esse aumento populacional. Há duas décadas ocorreu o primeiro crescimento imobiliário na região, fruto então da ação do Es- tado, que construiu milhares de casas populares, atraindo uma parcela da população mais pobre de Nijmegen, que passou a conviver com a população rural local. Na década de 1990, entretanto, deu-se um novo ciclo de crescimento com uma dinâmica distinta, já que vinculada a um processo mais amplo de diminuição da participação do poder público na área habitacional e fortalecimento do papel do mercado imobiliário, com a construção de casas mais caras, destinadas a um público de maior poder aquisitivo. ${ }^{12}$

Assim, se o primeiro ciclo de crescimento estava articulado ao II Plano Nacional de Desenvolvimento Espacial, de 1966, no qual o governo holandês "[...] anunciou uma política para criar novas moradias principalmente nas periferias e em 'cidades-satélites' em volta dos grandes centros urbanos", o segundo ciclo guarda relação com o IV Plano, de 1988, viabilizado por coalizões entre a direita e a esquerda e mais voltado às demandas de consumo e investimento das classes médias, quando então "[...] a participação do poder público na habitação diminui. Uma casa, anteriormente uma 'honra ao mérito', transformou-se - do ponto de vista econômico - em mercadoria e objeto de especulação" (Van Dijk, 1999/2000, pp. 9-10).

Em Beuningen, isso acarretou a vinda, a partir de 1990, de novos residentes, a maioria de classe média alta - 80\% vindos da região de Nijmegen (cidade que tem por volta de $150 \mathrm{mil}$ habitantes) e os demais de outros locais num raio de $50 \mathrm{~km}$-, para habitar os bairros De Haaghe, Den Balmend e De Beuningse Plas. Esse grupo de novos moradores - cujas casas abarcam $70 \%$ das construções locais dos últimos dez anos - pode ser considerado o principal responsável por uma série de mudanças na aldeia, além da introdução de novas redes de relações sociais. ${ }^{13}$

Naquela região, muitos iniciaram nos anos de 1990 o que em inglês é conhecido como bousing career, investindo seja em casas cujo valor aumenta sensivelmente ao longo dos anos, seja em compras e vendas sucessivas, para se chegar a um padrão habitacional mais elevado. ${ }^{14}$ Observa-se nesses novos empreendimentos residenciais uma curiosa síntese das regras ainda estipu- 
ladas pelo Estado - de herança modernista quanto ao formato geral das residências, com uma certa flexibilidade - ante as demandas do mercado - no que diz respeito à disposição de vários componentes da casa ou mesmo quanto à escolha de alguns modelos de moradia, permitindo-se a intervenção de arquitetos contratados individualmente para projetarem alguns espaços domésticos, porém dentro das diretrizes gerais do plano, o que ajuda compor uma determinada segmentação, numa espécie de paisagem "pósmoderna” peculiar. O condomínio Beuningse Plas, projetado em 1988 e em fase final de construção na época da pesquisa, contava em meados de 2001 com aproximadamente 450 casas, com previsão final do dobro desse número, nos três anos posteriores. Embora com poder aquisitivo maior do que a média dos moradores locais, os residentes dali eram vistos pelos empreendedores como que formando uma mixed community - constituída por especialistas, médicos, técnicos,
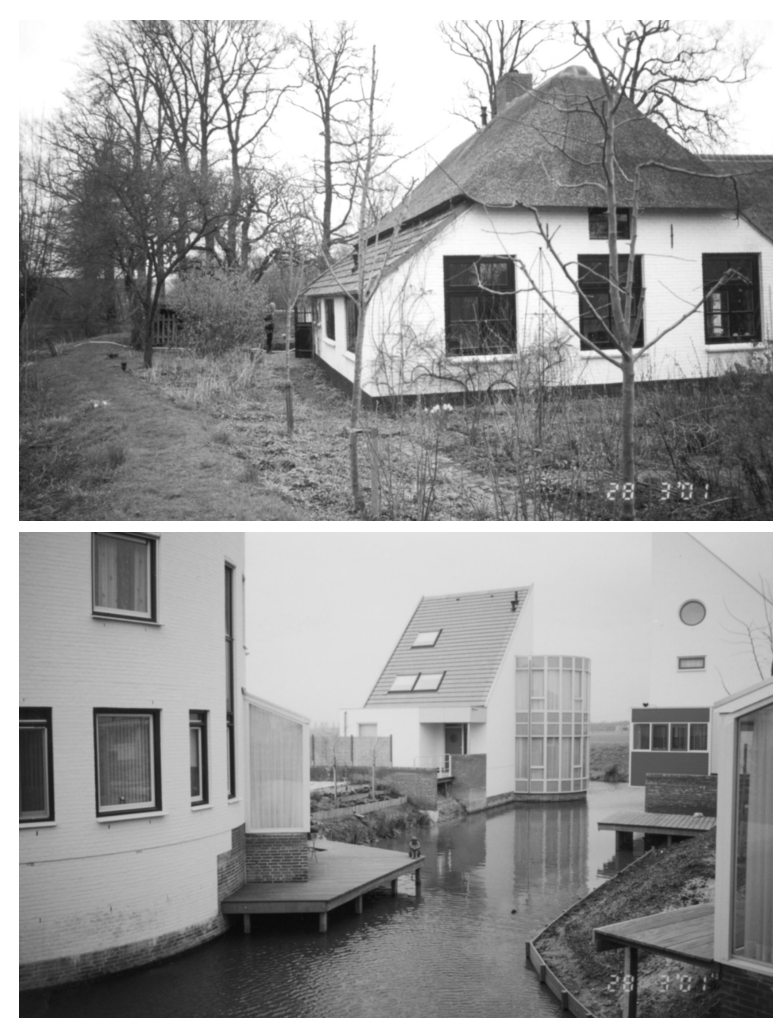

Contraste arquitetônico: moradia tradicional e residências "pós-modernas" em Beuningen (fotos de Heitor Frúgoli Jr.). professores universitários, jogadores profissionais de futebol e outros -, não considerados assim um grupo top, que ainda se pretendia atrair para a região da aldeia vizinha de Ewijk, com a oferta futura de casas ainda maiores e mais luxuosas. ${ }^{15}$

Mesmo que a diferença social e econômica entre os novos e os antigos residentes não seja grande - como no caso brasileiro dos condomínios residenciais situados em áreas periféricas ${ }^{16}-$, o grau de interação desse novo grupo com a comunidade já existente é efetivamente muito baixo. Alguns residentes mais antigos queixam-se que os novos moradores não têm quaisquer preocupações com as origens históricas e com a preservação da natureza da região - questão crucial na Holanda, em função da necessidade do controle constante do nível das águas dos rios da região em épocas de chuva ${ }^{17}-$, constituindo-se uma espécie de elite não comprometida com a aldeia.

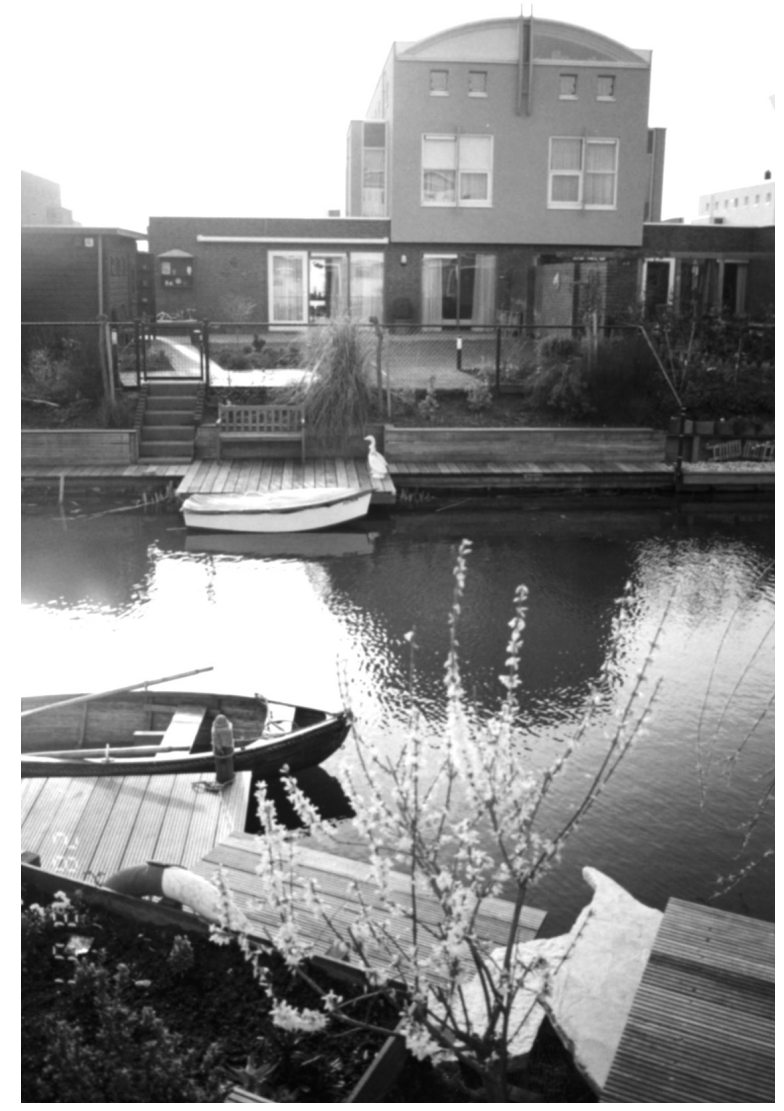

Fundos de quintal no condomínio Beuningse Plas: a busca recreativa da natureza (foto de Heitor Frúgoli Jr.). 
Segundo um desses moradores, somente a ameaça de ocorrência, há seis anos atrás, de uma grande inundação da área, com riscos aos diques do rio Waal (ao norte de Beuningen), despertou a nova população para esses temas, reforçando um provérbio mais recente que, diante do declínio do tradicional espírito de cooperação holandês, "só as tragédias parecem aproximar as pessoas". ${ }^{18}$

Outros residentes, todavia, reconhecem que os novos moradores não dispõem de tempo para estabelecer vínculos em Beuningen, já que passam a maior parte dos dias úteis no local de trabalho, a maioria em Nijmegen, e apenas pernoitam na aldeia, ${ }^{19}$ preferindo gozar o fim-de-semana em casa ou em atividades de recreação locais. ${ }^{20}$ Isso reitera e amplia um outro modo, já referido, de a população local caracterizar a região como "cidade-dormitório", ou seja, a visão de "cidadelazer", em que a natureza é antes tudo encarada em termos recreacionais. ${ }^{21}$

Isso não resume, entretanto, a visão que o próprio grupo dos mais recentes residentes - a maioria, como já foi referido, com empregos de alta renda - tem a respeito de sua inserção no local. Segundo um dos porta-vozes dos moradores do Beuningse Plas, quando em 1997 as primeiras casas foram ocupadas, sentia-se a necessidade de uma organização comunitária para fortalecimento interno, ante a demanda por uma série de melhorias. ${ }^{22}$ A propósito, é interessante frisar como muitas vezes um tipo de organização comunitária surge não em função das promessas dos empreendedores imobiliários, mas para dialogar com os mesmos em posição de força, por compromissos não cumpridos ou por demandas concretas. ${ }^{23}$ Isso levou à criação de um comitê formado por 222 moradores para negociações tanto com o governo local como com os construtores em torno de itens como obtenção de licenças para construções adicionais, compromissos quanto a novos equipamentos públicos, muros adicionais, sistema de aquecimento, segurança em geral, proteção para as crianças com relação à água etc. Segundo Merks, um dos representantes desse comitê, logo que os primeiros moradores vieram para aquela área, "ainda só havia vacas no entorno”. Durante um certo período, cerca de 25 pessoas atuaram de forma ativa pela obtenção desses equipamentos urbanos, sendo que no momento da entrevista, anos depois, a mobilização estava bem menor. Ao que parece, há um certo grau de sociabilidade entre os vizinhos, embora somente se observe uma mobilização mais visível quando estão em jogo interesses diretos dos moradores. Para eles, a natureza circundante constitui um inegável fator de atração, e pretende-se que esse condomínio seja o mais bonito local de moradia de toda a área, mas, na realidade, esses moradores têm muito pouco interesse por questões mais abrangentes ligadas à ecologia. Tal evidência revela-se inclusive na fala de Merks sobre uma fábrica de incineração de lixo das cercanias, criticada por muitos pela poluição diária, mas que não incomodaria os moradores desse bairro, já que "o vento leva o mau cheiro, durante a maior parte do ano, para outra direção". ${ }^{24}$

Nesse sentido, enquanto se fala do enfraquecimento dos laços comunitários tradicionais, os moradores mais recentes vêm constituindo, da sua forma e em prol de interesses particulares, uma outra espécie de comunidade, bastante exclusivista e pouco preocupada com temas mais abrangentes. Ainda que não seja uma gated community, ${ }^{25}$ há certas práticas e valores compartilhados que se assemelham a esse tipo de comunidade.

\section{Outras práticas e representações comunitárias em Beuningen: os laços tradicionais em jogo}

Há outros sinais de uma crescente urbanização, ou suburbanização, visíveis na constatação da fragilidade ou da dissolução dos assim chamados antigos laços comunitários. Atualmente, nos encontros da Fundação de Trabalho Social e Cultural local, é difícil definir atividades voltadas a demandas comuns ou consensuais da população, dada a crescente diversificação de interesses, típica de contextos urbanos. ${ }^{26}$ Vários moradores mais antigos - os dorpelingen (aldeões) - costumam dizer, desorientados, que "Beuningen não é mais Beuningen”, e as autoridades locais, vez por outra, lembram que "uma sociedade é mais do que apenas nossas casas". Muitos fazendeiros do lugar, por outro lado, afirmam que "Beuningen ain- 
da é a terra deles". É corrente também a idéia de que, por um século, a igreja católica tivera um papel importante no que diz respeito à manutenção do senso de comunidade, num local onde ainda hoje mais de $90 \%$ da população é católica (não necessariamente praticante) e cerca de 7 a $8 \%$ é protestante, ${ }^{27}$ ainda que, segundo Reichelt - que trabalha há vinte anos nessa Fundação e é seu atual coordenador -, desde a década de 1960 essa influência venha se diluindo. Outros dizem que antigamente a comunidade local se organizava, por exemplo, em torno de festas, como o carnaval, mas não foi possível averiguar a dimensão dessa prática, tampouco as razões de seu declínio. Muitas das atividades promovidas pela Fundação, dada a carência de subsídios públicos, ${ }^{28}$ dependem do envolvimento sobretudo de mulheres em trabalho voluntário. Nos últimos quinze anos, entretanto, tem aumentado sensivelmente a entrada feminina no mercado de trabalho, mesmo em áreas como essas. ${ }^{29}$ Constata-se um certo interesse, quanto aos adultos, em atividades ligadas à música folclórica ${ }^{30}$ e ao teatro amador. ${ }^{31}$ Observam-se, assim, práticas comunitárias pontuais e esparsas, permeadas por um discurso que remete muitas vezes a um passado áureo e mais ativo e que reivindica a "verdadeira Beuningen" aos antigos moradores.

Em outra direção, o discurso policial sobre o aumento do número de ocorrências em Beuningen é revelador de uma faceta distinta da organização comunitária local. ${ }^{32}$ Segundo Seerden, chefe do corpo policial local, tal índice vem crescendo porque, entre outros fatores, o controle social exercido pela coesão comunitária está diminuindo, ou seja, se antes um acontecimento um pouco mais grave podia ser mediado e resolvido pela própria vizinhança, hoje, num contexto de maior anonimato, necessita muito mais de intervenção policial. ${ }^{33}$

Quanto aos jovens, as atividades associativas mais recorrentes ocorrem nos esportes, com a prática do futebol, basquete e hóquei. Adolescentes da região costumam se queixar da falta de pontos de encontro ou de atividades de lazer, com exceção das esportivas. Como não há quase nada para se fazer em Beuningen, por vezes ocu- pam as ruas e, por causa do barulho que incomoda os mais velhos, acabam ocasionalmente atraindo a atenção da polícia. ${ }^{34}$ Ademais, não há escolas secundárias em Beuningen, o que faz com que a socialização escolar se dê apenas em Nijmegen, cidade que também constitui um ponto de encontro dos jovens nos fins de semana, em bares e discotecas. Isso acarreta, por vezes, o aumento de consumo de álcool e de drogas leves, vendidas em oito coffee shops dessa cidade, além de envolvimentos, bastante raros, em atos de delinqüência. ${ }^{35}$ Nesse sentido, há um projeto do município de transformar parte do pequeno shopping a céu aberto de Beuningen em uma espécie de centro cultural, na tentativa de criar pólos de convivência que concorram com os já existentes em Nijmegen. ${ }^{36}$ De um modo geral, os moradores parecem concordar com a necessidade de se criar espaços para o público juvenil, com a ressalva de que isso não seja perto de suas casas. ${ }^{37}$

Assim, procurando mapear as diversas representações locais sobre o tema "comunidade", pude observar, durante minha curta estadia em Beuningen, que não há realmente o mesmo grau de coesão, inclusive política, entre os habitantes mais antigos, comparando com o que já foi observado sobre os novos residentes. Há casos de moradores mais conectados às origens históricas da região, com uma visão crítica a respeito do recente desenvolvimento urbano na área, que apontam a falta de um debate mais consistente sobre os rumos da ocupação na cidade, a crise agrícola, a perda gradativa de espaços abertos e públicos, a necessidade de se diferenciar o compromisso com o meio ambiente de uma visão da natureza como simples objeto de recreação e, por fim, uma discussão da dependência do poder local aos novos empreendimentos imobiliários. Mas em virtude da debilidade dos laços sociais, essa postura não se traduz em ação política, são apenas movimentos pontuais e sem continuidade. ${ }^{38}$

\section{A questão da ecologia em Beuningen: o Groen Links}

A única fazendeira que entrevistei em Beuningen tem um perfil talvez atípico em relação 
aos "moradores rurais", já que possui uma fazenda de gado com preocupações ecológicas, é formada em psicologia e trata, recebendo subsídios do governo, ex-dependentes de droga, que trabalham voluntariamente na fazenda. ${ }^{39}$ Ainda que não tenha sido possível aferir o perfil social de outros fazendeiros, isso já é por si só revelador da complexidade que envolve o que pode ser considerado hoje o âmbito rural, no que diz respeito aos inúmeros elos que esse meio mantém com o contexto urbano.

Quanto às atividades comunitárias, o fato mais significativo é a participação dessa fazendeira no partido Groen Links, situado mais à esquerda do espectro político e que defende propostas ecológicas e ambientais. Contudo, esse partido não tem uma grande ressonância social em termos de engajamento da população local, ${ }^{40}$ mesmo por parte da parcela mais preocupada com temas ambientais. ${ }^{41}$

No prognóstico do Groen Links, toda a área a oeste de Nijmegen - onde está o município de Beuningen - constituirá nos próximos 25 anos, se houver desenvolvimento econômico, uma grande aglomeração de moradias e atividades industriais, com ausência de "áreas verdes". ${ }^{22}$ Isso inclusive já é uma realidade na aldeia da Weurt, vizinha a Nijmegen, próxima a uma área industrial e também ao rio Waal, onde circulam muitos navios diariamente, por vezes com cargas perigosas. Em recente pesquisa, o partido constatou que $80 \%$ dessa aldeia tem problemas advindos da poluição industrial, o que justifica ela ser conhecida como the impossible village. ${ }^{43}$ Teme-se que, a longo prazo, se configure um quadro urbano ainda mais "dramático" em toda a região, já que está previsto, ademais, a construção de um novo parque industrial ao norte de Weurt, na margem oposta do rio Waal, que incluirá uma nova estrada entre Weurt e Beuningen, a ser conectada a um centro de transporte multimodal. Além disso, várias áreas rurais de Beuningen deverão estar completamente ocupadas por casas de alto padrão, com a já mencionada previsão de futuras moradias na região vizinha de Ewijk, reforçando a alteração na composição social da população local e apontan- do, por conseguinte, para o possível acirramento de sua "desintegração social". ${ }^{44}$

Ainda segundo os membros do Groen Links, despertar a curiosidade sobre a natureza e desenvolver programas educacionais em torno da preservação ambiental é uma tarefa necessária e viável na região, além de, potencialmente, poder aproximar os novos e os antigos residentes. ${ }^{45}$ Há entretanto obstáculos a serem superados, pois de um modo geral cada distrito tem sua própria escola, o que dificulta o contato entre os filhos dos novos residentes e os filhos dos antigos moradores. ${ }^{46}$

Embora a agenda vinculada à ecologia encontre dificuldades para mobilizar a população no sentido de uma organização comunitária mais efetiva, pode-se afirmar a existência de um movimento ecológico na região, com prática e discurso voltados para a defesa de temas ambientais e que abriga tanto pessoas ligadas ao "campo" quanto à "cidade". Ainda que possa representar, de certo modo, uma forma de resistência ao tipo de desenvolvimento urbano em curso na região, o Groen Links talvez não se fortaleça justamente por representar uma corrente, por assim dizer, "anti-urbana". Por defender a manutenção de "áreas verdes", o partido é contra, por exemplo, certos investimentos produtivos, ${ }^{47}$ o que, de um lado, preservaria muitas regiões de um impacto ambiental destrutivo, mas, em última instância, poderia posicioná-las na contramão de um processo em curso - a urbanização do país.

Esse tema evidentemente exigiria um maior aprofundamento, pois também diz respeito às representações que sobretudo fazendeiros e novos moradores constroem sobre suas relações com a natureza. Em geral, os fazendeiros afirmam que exploram os recursos naturais em benefício da sociedade, o que legitima inclusive a utilização de fertilizantes químicos, pesticidas, tratores e mecanização da produção. Em contrapartida, os que vêm da cidade em busca do "campo" têm freqüentemente concepções românticas de uma natureza "intocada", dotada de valor intrínseco, ou então de "um campo como nos velhos tempos", com fertilizantes naturais, uso de arados etc. ${ }^{48}$ 


\section{Breves apontamentos sobre as propostas urbanísticas do poder local}

Se, como vimos, os antigos moradores e outras forças locais não conseguem superar determinadas divergências no sentido da construção de uma articulação mais consistente em termos políticos, o poder local, por sua vez, parece estar centrado basicamente no fornecimento de infra-estrutura para os novos empreendimentos imobiliários. Seguindo de certa forma uma tendência nacional, optou-se por uma política habitacional voltada para organizar e aperfeiçoar a implantação das casas de médio e alto padrão - prática ideologicamente identificada como a preocupação com "qualidade", em vez de "quantidade" -, além de incrementar os arredores com uma ênfase inegável ao lazer, que considera a natureza um espaço de recreação. Como propostas para o futuro, o poder local pretende incentivar edificações reconhecíveis e identificáveis para evitar a padronização típica dos subúrbios, procurando, além disso, "desfuncionalizar" as regiões, ou seja, impedir que Beuningen se torne apenas um local de moradia. Para isso, a criação de empregos é essencial, por meio do incentivo ao incremento de atividades comerciais ou então de uma aposta, num futuro mais longínquo, nos assim chamados "escritórios dentro de casa". Embora tais medidas façam parte do plano diretor, há muitos obstáculos práticos, mas o principal problema reside na perspectiva de se alcançar apenas resultados duvidosos: sem entrar no mérito de todos os aspectos envolvidos, cabe observar que não basta uma arquitetura "arrojada" ou "diferenciada" para evitar padronizações suburbanas $^{49}$ e que, quanto à emergência de novos empregos, os chamados "escritórios em casa" tenderiam a privilegiar os novos residentes, reforçando assim a diferenciação social que se observa em toda região. ${ }^{50}$

\section{Comentários finais}

Num quadro em permanente mudança, com transições de uma paisagem rural para um contexto urbano e com fortalecimento do mercado em detrimento do Estado, aqueles que mais se beneficiam por esse processo - os novos residentes - são justamente os que têm conseguido se organizar para fazer valer suas demandas diante do poder local, o qual, aliás, muito já tem feito em favor desses interesses. Em outras palavras, esses grupos são mais capazes de articular, nesse contexto, uma espécie de comunidade mais visível, qual seja, a de proprietários que valorizam os interesses privados, definidos em torno da casa e dos arredores mais imediatos, sempre mais importantes que a cidade como um todo.

Este estudo de caso pode ser relacionado com outras pesquisas sobre a busca de "ambientes campestres" por setores médios e altos das sociedades européias, já que há evidências de fenômenos similares em curso não só na Holanda, mas também em outros países, como França, Alemanha, Suíça e Portugal. Dessa forma, é plausível considerar a idéia de um processo sociocultural mais abrangente - levando em conta obviamente as distintas configurações de cada caso -, envolvendo especialmente grupos de classe média e alta que vêm se deslocando dos grandes centros urbanos para espaços onde as dimensões urbana e rural estão razoavelmente entrelaçadas. Esse tipo de migração é acompanhado por um discurso ou um imaginário fortemente marcado tanto pela crítica a aspectos negativos da cidade, como pela busca de maior contato com uma "natureza" idealizada e, ademais, a existência de terrenos mais baratos e a perspectiva de uma rápida valorização imobiliária podem compensar o ônus do deslocamento cotidiano para o trabalho A mudança de modo de vida tem em vista sobretudo o lazer e a recreação, além de maior visibilidade e poder que esses grupos adquirem no novo espaço, organizando-se de forma comunitária para a defesa de seus interesses. ${ }^{51}$

Quanto aos grupos sociais e às instituições mais antigas de Beuningen, observa-se, de um lado, a nostalgia de uma organização comunitária que, caso tenha realmente existido, já não há mais no presente. Isso, entretanto, exigiria um estudo mais aprofundado, pois também é aceitável a hipótese de que se trata de uma memória coletiva viva, decorrente de graus significativos de convivência e 
coesão no passado, mas que hoje não mais representaria capitais social e cultural valiosos. ${ }^{52}$

De outro lado, as divergências políticas também impedem os antigos moradores de se organizarem para discutir os problemas e transformar seus valores em práticas concretas, malgrado o surgimento de um tipo de movimento ecológico que tenta traduzir certas insatisfações em ações de resistência, mas que não consegue muita adesão em virtude de uma concepção de não intervenção na natureza que dá sentido à sua ação, mas que entra em conflito com outras representações sociais sobre o tema.

A experiência propiciada por esta pesquisa suscitou a idéia de que a tentativa de se resgatar a identidade ou o sentido de comunidade de um povoado, típica de contextos tradicionais e situada em planos imaginários, precisa ser definitivamente repensada mesmo em contextos como o da presente abordagem, marcados por uma urbanização incipiente. É preciso contemplar na análise os conflitos existentes entre os diversos grupos sociais, cujo tempo de moradia, composição social e formas de coesão interna vêm definindo as práticas e sobretudo os discursos da população, revelando os embates por posições sociais privilegiadas em regiões que estão em fase de mudança, como a estudada nesta pesquisa.

O tema da comunidade recoloca-se como um problema nesse novo contexto, visto que o desenvolvimento da urbanização não significa a dissolução desse conceito, mas uma mudança de perspectiva. A noção de comunidade persiste como uma estratégia discursiva, articulada a determinadas práticas concretas, ambas vinculadas, por sua vez, a objetivos políticos.

Estamos habituados a considerar extremamente positiva a organização política de comunidades, sobretudo quando se trata de grupos oriundos das classes populares. Contudo, não se deve perder de vista que essa estratégia discursiva pode estar sendo usada e acionada por grupos mais privilegiados, cuja coesão interna lhes confere maior visibilidade, garantindo a esses grupos o pronto atendimento de suas demandas, em detrimento de outros interesses legítimos em jogo.
Nesse caso, estamos diante de um contexto urbano efetivamente heterogêneo - o que não quer dizer que essa não seja também uma característica do meio rural, mas sob outros ângulos -, assentado sob uma perspectiva plural de comunidade. Talvez o principal desafio nesse contexto seja evitar que uma comunidade específica detenha o monopólio das representações e das práticas sociais. Isso só é possível, evidentemente, com o desenvolvimento de uma esfera pública mais consistente, que permita estabelecer a comunicação e o debate entre as distintas posições, buscando romper os "muros simbólicos" que marcam a sociedade diversificada, a qual gradativamente vem se desenvolvendo em Beuningen.

\section{NOTA}

1 Trata-se de um projeto de arte pública, que visa à intervenção em espaços no sentido de explicitar aspectos urbanos e sociais problemáticos e de apontar soluções inovadoras, envolvendo a colaboração multidisciplinar. Para mais detalhes, cf. Venhuizen e Timmermans (2000) e Meurs (2001).

2 A expressão assume aqui um sentido muito distinto do que representa no Brasil. Entre nós, também expressa a idéia de cidades desertas, porém pobres, sem infra-estrutura ou em processo de decadência.

3 Este texto, que se originou parcialmente do relatório de pesquisa traduzido para o holandês e publicado na internet (Frúgoli Jr., 2001a), baseia-se, portanto, em trabalho de campo realizado durante uma semana de visitas e contatos com vários moradores locais, ao final de março de 2001, numa consultoria para o projeto "The invention of the wetland model", organizado pelo Bureau Venhuizen, sob os auspícios da Fundação Van Weurt tot Deest. Apesar da grande coleta de dados que foi feita durante pesquisa, um estudo em profundidade exigiria mais tempo, para se poder analisar outros aspectos significativos do universo abordado e de seu cotidiano. Todavia, os encontros e, sobretudo, as entrevistas com pessoas de diferentes grupos e instituições, além da minha condição distanciada de estrangeiro, permitiram-me reunir um razoável conhecimento 
sobre a realidade local. Cabe ainda comentar que, ante o olhar europeu sobre países colonizados ou periféricos, não deixa de ser curiosa a possibilidade de um antropólogo brasileiro lançar seu olhar sobre o contexto holandês, o que em parte foi possível graças à tradição de intercâmbios na Holanda.

4 Dada a amplitude do tema, ver os termos enfocados por Berman (1986). Para uma crítica do conceito, cf. Latour (1999).

5 A esse respeito, ver Fernandes (1973) e, sobretudo, os artigos de Tönnies (1973 [1887]) e Weber (1977 [1921]). Para as problematizações levantadas posteriormente, ver Wirth (1973 [1933]).

6 Por outro lado, a relação entre campo e cidade não pode ser compreendida sem a contemplação de outras relações. Williams ressalta que o termo metrópole designava tanto uma grande cidade industrial do século XIX (em contraponto às áreas rurais), como as relações entre os países que se situam no centro do poder econômico, político e cultural, e os países subdesenvolvidos, ou seja, já era um conceito que abarcava relações de poder não só decorrentes do crescimento urbano, assim como de posições de domínio no contexto internacional (1989 [1973], pp. 374-375).

7 Como mostra Marins, o projeto original de Ebenezer Howard, pioneiro na criação das garden cities, "era uma proposta de habitação suburbana para classes médias e pobres, idealizada para atenuar as precárias condições de moradia das grandes metrópoles industriais inglesas", ainda que, de um modo geral - como se pode ver no caso de São Paulo -, os bairros inspirados nas "cidades-jardins" não tenham sido efetivamente destinados aos mais pobres (1998, pp. 181-187).

8 Neste contexto são claras as continuidades entre os plano rural e urbano, se atentarmos, por exemplo, para como esse tema foi discutido pelo pensamento social brasileiro. Basta mencionarmos a ênfase de Gilberto Freyre na "urbanização do patriarcalismo" como uma das chaves explicativas da dinâmica cultural de nossas cidades (cf. Freyre, 1961 [1936]).

9 Nesse caso, o espaço rural seria definido sobretudo como um modo particular de utilização do espaço e de vida social (cf. Kayser, 1990, p. 29).
10 Essa crítica encontra-se aprofudada numa abordagem posterior, desta vez enfocando o modo de vida de migrantes camponeses que viviam em áreas periféricas da Cidade do México (Lewis, 1965), o que levou o autor a tecer novas críticas, então centradas nos pressupostos de Wirth quanto à cultura urbana. Em linhas gerais, a comunidade formada por esses grupos estava razoavelmente integrada à vida urbana e compunha redes familiares extensas e relativamente estáveis, ao contrário do que se esperava quanto a um suposto processo de "desorganização social" que marcaria a vida urbana inicial desses grupos. Ademais, a vida religiosa continuava fortalecida, era recorrente a utilização do sistema de compradazgo - predominante no campo - em várias práticas informais de sobrevivência e, por fim, muitos ainda recorriam ao uso de ervas e crenças domésticas no combate às doenças (cf. Oliven, 1985, pp. 16-18).

11 Entrevista com o conselheiro municipal da cultura e planejamento urbano, Guus van der Heijden, pertencente ao Partido Democrata-Cristão (Christen Democratisch Appèl - CDA), em 26/3/2001. Todas as entrevistas ou foram feitas em inglês, ou traduzidas do holandês para o inglês e vice-versa, por Hans Venhuizen e Maureen Timmermans.

12 Entrevista com Van der Heijden (26/3/2001), cit., e com Piet Snellaars, diretor do Departamento de Planejamento Espacial de Beuningen e secretário da Fundação Van Weurt tot Deest, em 27 e 28/3/2001.

13 Cf. dados fornecidos por Snelaars em entrevista (27 e 28/3/2001), cit., e por entrevista com um dos porta-vozes dos proprietários do condomínio Beuningse Plas, Robert Merks, gerente de vendas da indústria de semicondutores, que trabalha em Nijmegen, em 28/3/2001.

14 Em Beuningen, uma casa no valor de Df 200 mil (US\$ 77,8 mil) podia chegar a valer, quatro anos depois, Df 350 mil (US\$ 136,1 mil). Na época da pesquisa, uma casa em estilo "pós-moderno", com área de 500 m2, custava por volta de Df 600 mil (US\$ 233,4 mil) (entrevista com Snelaars, 27 e 28/3/2001, cit.).

15 O custo dessas construções estava, na época, na faixa dos Df 1 milhão (US\$ 389,1 mil) (entrevista com Snelaars, 27 e 28/3/2001, cit., e com Guido Wouterson, planejador urbano do Departamento de Planejamento Espacial de Beuningen, em 28/3/2001). 
16 Refiro-me aqui sobretudo ao "modelo Alphaville", analisado por Caldeira (2000), atualmente em fase de expansão nacional e internacional. Cf. Folha de São Paulo, 13/1/2002, p. 1. cad. Imóveis.

17 Quase 25\% do território holandês, área que abriga cerca de $60 \%$ da população, está abaixo do nível do mar. Grandes extensões do território foram conquistadas de zonas onde, antigamente, só existia água (cf. www.holandahoje.com.br). Isso ajuda a definir a peculiaridade tanto da natureza, como do meio rural na Holanda.

18 Entrevista com Ecco Smith, engenheiro que trabalha em Nijmegen, em 28/3/2001. Ele é porta-vOz de um grupo que critica os novos desenvolvimentos espaciais em Beuningen.

19 Morar numa cidade e trabalhar em outra tem se tornado corriqueiro na Holanda, dadas as pequenas distâncias entre os grandes centros urbanos do país. Cf. entrevista com Paul Meurs, em Frúgoli Jr. e Cartum (2000).

20 Existe um projeto para a construção de um lago de 50 hectares com um pequeno porto, para o uso de barcos, natação no verão, esqui no inverno, pesca etc. Embora seja de acesso público, está previsto uma conexão com o condomínio Beuningse Plas, o que seria muito útil para os moradores, já que eles usam barcos nos pequenos canais que ligam os fundos de quintais (entrevista com Snelaars, 27 e 28/3/2001, cit.).

21 Entrevista com Smith (28/3/2001), cit., com Snelaars (27 e 28/3/2001), cit., e conversa informal com Hans Venhuizen, coordenador do presente projeto.

22 Entrevista com Merks (28/3/2001), cit.

23 Foi o que ocorreu, por exemplo, no caso da Celebration, uma comunidade totalmente planejada pela Disney Corporation na Flórida, na qual os moradores tiveram muitos problemas com a empresa responsável pela construção das casas - atrasos na entrega ou vários defeitos de fabricação -, além de regras inflexíveis arbitrando sobre detalhes como possíveis mudanças nas fachadas que pudesse alterar os estilos existentes. Essas circunstâncias levaram então à criação de uma associação local de proprietários, para fortalecê-los na dura negociação com o setor imobiliário e com a própria Disney (cf. Ross, 1999 apud Frúgoli Jr., 2001b).
24 Sobre a possibilidade da construção de um poço de escavação de areia de 500 hectares ao sul de Winssen, que se ligaria a um porto no rio Waal para transporte do material, com inegáveis impactos ambientais, a posição também é explícita: "Sendo honesto, eu não estou nem aí, não me importo. Se isso não está bem diante da nossa porta, nós não nos importamos tanto" ["To be honest, I don't give a shit, I don't care. If it's not directly on the doorstep, we don't care so much"] (entrevista com Merks, tradução do autor, 28/3/2001, cit.).

$25 \mathrm{Na}$ gated community configura-se um contexto de violência urbana, o que é relativizado pelos dados numéricos sobre criminalidade em Beuningen - em geral, baixos em número absoluto, ainda que não necessariamente em número relativo. Houve, por exemplo, 370 arrombamentos e furtos de veículos em 1999, além do roubo de 230 bicicletas, importante meio de transporte no país (entrevista com Joop Seerden, chefe do corpo policial de Beuningen, concedida em 29/3/2001), o que, numa população de 26 mil habitantes, representa uma ocorrência para cada setenta pessoas no período de um ano. Em Barueri, onde está situado o condomínio Alphaville, houve, por exemplo, 889 furtos e roubos de veículos em 2001 (cf. Sammogini, 2002, p. 5), mas a população é de aproximada 208 mil habitantes, e, portanto, tem-se uma relação de uma ocorrência para cada 233 pessoas, no mesmo período. De toda forma, essas estatísticas não permitem generalização, ainda mais porque, nos crimes contra a pessoa, houve, em 2000, cinco estupros e somente um assassinato em Beuningen (há quem diga que na Holanda o assassinato de Pim Fortuyn, polêmico líder político ligado à extrema direita, em 6/5/2002, teria sido o primeiro crime político no país após o assassinato de Guilherme de Orange, no século XVI). Foram também registrados 130 arrombamentos de casas em 1999, o que, provavelmente, levou a um aumento do consumo de câmeras e dispositivos de segurança. Ainda assim, nenhuma menção mais explícita à questão da violência apareceu nos depoimentos, com exceção do discurso policial (entrevista com Seerden, 29/3/2001, cit.).

26 É importante frisar que essa diversificação não se articula, no caso de Beuningen, a nenhuma comunidade ou enclave étnico significativo e visível, ao 
contrário do que vem ocorrendo nos principais centros urbanos holandeses, com a presença, entre outros, de turcos e marroquinos, além dos surinameses, antilhanos e caboverdianos (cf. Sansone, 1991). Entretanto, a política holandesa de dar asilo a uma grande parcela de refugiados, alocando-os em várias regiões do país, com assistência e acompanhamento por um período de dois anos, tornou regular o número de refugiados que aflui todo ano para a região de Beuningen. Calcula-se que na época houvesse por volta de 75 refugiados de origens étnicas variadas que viviam no município de Beuningen (apenas 0,2\% da população total): entre 1995 e 1996 predominaram os bósnios; de 1997 a 1999, cerca de $30 \%$ dos que chegaram à região eram curdos do Iraque; e nos últimos cinco anos, presenciou-se um número significativo de africanos da Somália e do Zaire (entrevista com Ramona, que trabalha na Fundação de Refugiados de Beuningen, em 29/3/2001). Em 2000, 43.890 pessoas solicitaram asilo à Holanda, número suplantado apenas pelo Reino Unido e pela Alemanha em toda a Europa (cf. Folba de São Paulo, 20/2/2001, p. A11).

27 São números distintos da média nacional, em que 34,5\% são católicos e 26,9\%, protestantes (cf. Rossi, 2002, p. A13).

28 O orçamento anual da Fundação de Trabalho Social e Cultural era, na época, de Df 80 mil (US\$ 31,1 mil).

29 Com isso não se diz mais na Holanda expressões como "viúvas verdes" ou "alcoólatras de sherry", atribuídas às esposas que antes ficavam sozinhas nos lares e, de certa forma, "presas" nas aldeias (com base em comentários de Geert Banck, da Universidade de Utrecht, ao presente trabalho).

30 Há uma fanfarra de Beuningen, fundada em 1934 e, ao que parece, ainda ativa nos dias de hoje.

31 Cf. entrevista com Will Reichelt, coordenador da Fundação de Trabalho Social e Cultural de Beuningen, em 29/3/2001.

32 Ver a análise dos dados disponíveis em nota prévia.

33 A noção de comunidade é novamente acionada, pautada aqui na idéia da necessidade de um "policiamento orientado ou em parceria com a comunidade”. Essa idéia já havia sido formulada há cinco anos como parte da política holandesa na área da segurança, e passou a ser considerada necessária também em Beuningen, já que, segundo o chefe do corpo policial, a polícia estaria atuando com equipamentos e recursos humanos insuficientes, ao dispor de apenas um carro e quarenta policiais para as quatro aldeias (entrevista com Seerden, 29/3/2001, cit.).

34 Entrevista com Reichelt (29/3/2001), cit., e com Snelaars, (27 e 28/3/2001), cit. Segundo Seerden (entrevista em 29/3/2001, cit.), houve, em 1999, 240 queixas contra distúrbios juvenis à ordem, número que caiu para 130 em 2000, sendo que cerca de 70\% dessas queixas se concentram na aldeia de Beuningen.

35 Entrevista com Reichelt (29/3/2001), cit., e com Seerden (29/3/2001), cit. Como afirma Sansone, "Hoje em dia nos Países Baixos o termo coffee-shop refere-se a uma lanchonete sem licença de funcionamento, embora tolerada, geralmente de propriedade informal e dirigida por um grupo de jovens. As coffee-shops giram em torno da venda e do uso de drogas leves [toleradas no país] e, de certo modo, funcionam como pequenos clubes de assistência a jovens" (1991, pp. 131-132).

36 Entrevista com Van der Heijden (26/3/2001), cit.

37 Entrevista com Snelaars (27 e 28/3/2001), cit.

38 Por vezes observa-se uma mobilização como, por exemplo, a formação de uma comissão de oito moradores de aldeias próximas - sobretudo acadêmicos -, representando sessenta habitantes das cercanias, para dialogar com o governo a respeito da instalação do poço de escavação de areia ao sul de Winssen. A mobilização visava a minimizar futuros impactos ambientais que a construção e o funcionamento do poço inevitavelmente acarretariam (entrevista com Smith, 28/3/2001, cit.).

39 Com base em entrevista com Marlies Hermans, em 28/3/2001. Essa fazendeira é vista por alguns como uma pessoa "esquisita", talvez pelo fato de lidar com drogados, ou nas palavras de alguns moradores da cidade, pelo costume de "comer numa mesa suja" ou por "estar sempre mal-cheirosa". Trata-se de um tipo de construção estigmatizante que lembra as observações de Norbert Elias (1990 [1939]) quanto à adoção de hábitos "civilizados" como demarcação de distinções sociais, nesse último caso entre habitantes da cidade e do campo. 
$40 \mathrm{Na}$ época, a média nacional de eleitores do partido era $7 \%$, sendo a maioria de elevado nível educacional (universitários, educadores, médicos etc.).

41 Entrevista com Franz Houben, dirigente local do partido político Groen Links, em 29/3/2001.

42 Trata-se de áreas onde não há planejamento de atividades, com exceção das regiões próximas aos diques, protegidas pelo Estado (entrevista com Houben, 29/3/2001, cit.).

43 Entrevista com Houben (29/3/2001), cit., e com Wouterson (28/3/2001), cit.

44 Entrevista com Houben (29/3/2001), cit.

45 Idem, ibidem.

46 Idem, ibidem.

47 A comissão que negociou com o governo sobre a construção do poço de areia na região foi criticada pelo dirigente local do Groen Links, Franz Houben, por não ter combatido com mais vigor esse futuro empreendimento industrial (entrevista com Houben Houben, 29/3/2001, cit.).

48 Sou grato aos comentários de Tony Robben (Universidade de Utrecht) a esse respeito.

49 Ver, por exemplo, como as chamadas "paisagens pósmodernas" não deixam de apresentar certos aspectos homogeneizantes (cf. Frúgoli Jr., 2000, pp. 178-203).

50 Entrevista com Snelaars (27 e 28/3/2001), cit., e Van der Heijden (26/3/2001), cit. Para Guido Wouterson da equipe de planejamento urbano de Beuningen, que viera há um ano com a família da pequena cidade de Leiden, em busca de melhor qualidade de vida -, em Beuningen "o mundo agrícola estava praticamente desaparecendo na região" e o "urbano e o rural seriam mundos separados" (entrevista com Wouterson (28/3/2001), cit.).

51 Nesse sentido, foi esclarecedora a fala de Catherine Bidou-Zachariasen (2002) no XXVI Encontro Anual da Anpocs, quando comentou brevemente as pesquisas que realizou na França sobre o uso do espaço urbano pelas novas classes médias. Em particular, em um estudo de caso sobre os significados da organização associativa de um grupo de novos moradores num pequeno vilarejo, a autora mostra que esses moradores buscam reinventar tanto o espaço urbano, como o papel político que desempenham no local.
52 Agradeço novamente os comentários de Geert Banck a respeito desse tema.

\section{BIBLIOGRAFIA}

BANCK, Geert. (1998), Dilemas e símbolos: estudos sobre a cultura política do Espírito Santo. Vitória, Instituto Histórico e Geográfico do Espírito Santo (Cadernos de História, 13).

BEELDKWALITEITSPLAN Gemeente Beuningen. (1995), Beunigse Plas. Beuningen, Beeldkwaliteitsplan Gemeente Beuningen.

BERMAN, Marshall. (1986), Tudo que é sólido desmancha no ar. São Paulo, Cia. das Letras (tradução de Carlos Felipe Moisés e Ana Maria L. Ioriatti).

BIDOU-ZACHARIASEN, Catherine. (2002), “À propos de la "service class": les classes moyennes dans la sociologie britannique". Trabalho apresentado no XXVI Encontro Anual da Anpocs, Caxambu.

BOURDIEU, Pierre. (1989), O poder simbólico. Lisboa, Difel (tradução de Fernando Tomaz).

CALDEIRA, Teresa P. do R. (2000), Cidade de muros: crime, segregação e cidadania em São Paulo. São Paulo, Edusp/Editora 34.

CANCLINI, Néstor G. (1997), "Urban cultures at the end of the century: the anthropological perspective". International Social Science Journal, 155: 345-356, Oxford, set.

DAVIS, Mike. (1990), City of quartz: excavating the future in Los Angeles. Londres, Verso.

DURHAM, Eunice. (1973), A caminho da cidade: a vida rural e a migração para São Paulo. São Paulo, Perspectiva.

(1986), "A pesquisa antropológica com populações urbanas: problemas e perspectivas", in Ruth Cardoso (org.), A aventura antropológica, São Paulo, Paz e Terra. 
ELIAS, Norbert. (1990 [1939]), O processo civilizador: uma história dos costumes. Rio de Janeiro, Jorge Zahar (tradução de Ruy Jungmann).

ELIAS, Norbert \& SCOTSON, John L. (2000 [1965]), Os estabelecidos e os outsiders: sociologia das relações de poder a partir de uma pequena comunidade. Rio de Janeiro, Jorge Zahar (tradução de Vera Ribeiro).

FERNANDES, Florestan (org.) (1973), Comunidade e sociedade: leituras sobre problemas conceituais, metodológicos e de aplicação. São Paulo, Nacional/Edusp.

FREYRE, Gilberto. (1961 [1936]), Sobrados e mucambos: decadência do patriarcado rural e desenvolvimento do urbano. 3 ed., Rio de Janeiro, José Olympio.

FOLHA DE SÃO PAULO. (2001), "Onda de imigrantes ilegais faz União Européia rever asilo". São Paulo, p. A11, 20/fev.

. (2002), "Alphaville vai ao interior e ao exterior”. São Paulo, pp. 1-2 (Caderno Imóveis 1), 13/jan.

FRÚGOLI JR., Heitor. (2000), Centralidade em São Paulo: trajetórias, conflitos e negociações na metrópole. São Paulo, Cortez/Edusp/Fapesp.

. (2001a), "Beuningen: de verschillende fases van dorpen in een proces van verandering", in $\mathrm{H}$. Venhuizen (ed.), The invention of the wetland model, Rotterdam, Van Weurt tot Deest Foundation/Bureau Venhuizen (http://www.uiterwaardenmodel.nl).

. (2001b), "Celebration: a busca da cidade perfeita e a vida real". EURE - Revista Latinoamericana de Estudios Urbano Regionales, XXVII, 81: 123-127, Santiago do Chile, set.

FRÚGOLI JR., Heitor \& CARTUM, Marcos. (2000), "Entrevista com o arquiteto Paul Meurs". Portal de Arquitetura e Urbanismo Vitruvius (coord. de Abillio Guerra), São Paulo, nov. (http://www.vitruvius.com.br/entrevista/meurs/meurs.asp).

GARREAU, Joel. (1991), Edge cities: life in the new frontier. Nova York, Anchor Books/ Doubleday.

GIROUARD, Mark. (1985), Cities and people: a social and architectural history. New Haven/Londres, Yale University Press.

HANNERZ, Ulf. (1980), Exploring the city: inquiries toward an urban anthropology. Nova York, Columbia University Press.

HOLANDA HOJE: Arte, design, urbanismo e responsabilidade social. (2003), Consulado Geral dos Países Baixos. São Paulo, mar. (http://www.holandahoje.com.br).

HOLSTON, James \& APPADURAI, Arjun. (1996), "Cities and citizenship". Public Culture, 8 (2): 187-204, Chicago.

JACKSON, Kenneth T. (1985), Crabgrass frontier: the suburbanization of the United States. Nova York, Oxford University Press.

KAYSER, Bernard. (1990), La renaissance rurale: sociologie des campagnes du monde occidental. Paris, Armand Colin.

KOWARICK, Lúcio. (2000), Escritos urbanos. São Paulo, Editora 34.

LANDMAN, Karina. (2000), "An overview of enclosed neighbourhoods in South Africa". CSIR Publication, Pretoria, BOU/I 187.

LATOUR, Bruno. (1999), Jamais fomos modernos. São Paulo, Editora 34 (tradução de Carlos Irineu da Costa).

LEWIS, Oscar. (1951), Life in a Mexican village: Tepoztlán restudied. Urbana, University of Illinois Press.

(1965), "Further observations in the folk-urban continuum and urbanization with special reference to Mexico City", in P. M. Hauser e L. F. Schnore (eds.), The study of urbanization, Nova York, Wiley.

MARINS, Paulo C. G. (1998), "Habitação e vizinhança: limites da privacidade no surgimento 
das metrópoles brasileiras", in N. Sevcenko (org.), História da vida privada no Brasil, vol. 3, São Paulo, Cia. das Letras.

MEURS, Paul. (2001), "The washland-model", in H. Venhuizen (ed.), Venhuizen Conceptmanagement Art and Urbanism, Rotterdam, Bureau Venhuizen.

OLIVEN, Ruben George. (1985), A antropologia de grupos urbanos. Petrópolis, Vozes.

RAULIN, Anne. (2001), Anthropologie urbaine. Paris, Armand Colin.

REDFIELD, Robert. (1947), "The folk society". American Journal of Sociology, 52 (4).

(1953), The primitive world and its transformations. Ithaca/NY, Great Seal Books.

(1955), The little community. Chicago, University of Chicago Press.

. (1974 [1930]), Tepoztlán: a Mexican village - A study of folk life. Chicago/Londres, The University of Chicago Press.

ROSS, Andrew. (1999), The celebration chronicles: life, liberty, and the pursuit of property value in Disney's new town. Nova York, Ballantine Books.

ROSSI, Clóvis. (2002), "Holanda 'perde inocência' na eleição de hoje”. Folha de São Paulo, p. A13, 15/maio.

SAMMOGINI, Alexandre. (2002), "Maioria só tem segurança básica". Folba de São Paulo, p. 5 (Caderno Imóveis), 18/ago.

SANSONE, Lívio. (1991), "Da cultura 'creole' à subcultura negra: a nova etnicidade negra dos jovens 'creole' surinameses de classe baixa em Amsterdam". Estudos Afro-Asiáticos, 20: 121-134, jun.

SCHORSKE, Carl E. (2000), Pensando com a história: indagações na passagem para o modernismo. São Paulo, Cia. das Letras (tradução de Pedro Maia Soares).

THE ECONOMIST. (2002), "A survey of The Netherlands". The Economist Newspaper, pp. 1-18, Londres, maio.
TÖNNIES, Ferdinand. (1973 [1887]), "Comunidade e sociedade como entidades típicoideais", in F. Fernandes (org.), Comunidade e sociedade: leituras sobre problemas conceituais, metodológicos e de aplicação, São Paulo, Nacional/Edusp.

VAN DIJK, Hans. (1999/2000), "Emancipação. Do movimento ao mercado: ativismo e consumismo a partir de 1968", in M. Risselada (curador), Além do modernismo: três momentos da arquitetura do pós-guerra na Holanda. IV Bienal Internacional de Arquitetura em São Paulo, Universidade de Delft, Nai e The Urban Fabric.

VENHUIZEN, Hans \& TIMMERMANS, Maureen. (2000), The invention of the wetland model. Rotterdam, Bureau Venhuizen, datilo.

WEBER, Max. (1973 [1921]), "Comunidade e sociedade como estruturas de socialização”, in F. Fernandes (org.), Comunidade e sociedade: leituras sobre problemas conceituais, metodológicos e de aplicação, São Paulo, Nacional/Edusp.

WILLIAMS, Raymond. (1989 [1973]), O campo e a cidade na bistória e na literatura. São Paulo, Cia. das Letras (tradução de Paulo Henriques Britto).

WIRTH, Louis. (1973 [1933]), "Delineamento e problemas da comunidade", in F. Fernandes (org.), Comunidade e sociedade: leituras sobre problemas conceituais, metodológicos e de aplicação, São Paulo, Nacional/Edusp.

(1987 [1938]), "O urbanismo como modo de vida”, in O. G. Velho (org.), $O$ fenômeno urbano, 4 ed., Rio de Janeiro, Guanabara.

WOORTMANN, Klass A. A. W. (s. d.), "A antropologia brasileira e os estudos de comunidade". Universitas, 11: 103-140, Salvador. 


\section{A DISSOLUÇÃO E A REINVENÇÃO DO SENTIDO DE COMUNIDADE EM BEUNINGEN, HOLANDA}

\author{
Heitor Frúgoli Jr.
}

\section{Palavras-chave}

Comunidade e sociedade; Rural e urbano; Mudança sociocultural.

A cidade de Beuningen conta, junto a outros três povoados próximos, com uma população de 26 mil habitantes. Essa região sofreu um primeiro ciclo de crescimento há duas décadas, promovido pelo Estado, e passa, atualmente, por uma nova expansão imobiliária no interior de um processo mais amplo de diminuição do papel do poder público na habitação e de fortalecimento do mercado. Com base em uma breve pesquisa de campo na cidade, o autor analisa certos conflitos sociais ali existentes, com ênfase crítica no conceito de comunidade e em contrapontos entre os planos rural e urbano, discutindo os significados que essas noções adquirem no presente caso.

\section{DISSOLUTION AND REINVEN- TION OF THE SENSE OF COMMU- NITY IN BEUNINGEN, HOLLAND}

Heitor Frúgoli Jr.

\section{Key words}

Community and society; Rural and urban; Sociocultural change.

The village of Beuningen and three other adjacent settlements have around 26 thousands inhabitants today. A first cycle of urban growth, promoted by the State, occurred approximately twenty years ago in the area, which has recently been passing through a new real estate expansion, as part of a broad process marked by the diminishing public policy on inhabitation and the market consolidation in the housing field. Based on a brief field research, the article analyzes some current social conflicts, critically emphasizing the concept of community and some counterpoints between the rural and urban dimensions, discussing the meanings that such notions have acquired in the present case.

\section{LA DISSOLUTION ET LA RÉINVEN- TION DU SENS DE COMMUNAUTÉ À BEUNINGEN, HOLLANDE}

Heitor Frúgoli Jr.

\section{Mots-clés}

Communauté et société; Rural et urbain; Changement socio-culturel.

La région formée par la ville de Beuningen et trois autres villages voisins regroupe 26 mil habitants. Cette région a déjà subit un premier cycle de croissance, promu par l’état, il y a vingt ans, et passe par une nouvelle expansion de l'immobilier dans le cadre d'un processus plus large de renforcement du marché, avec la production de maisons plus chères, ce qui a attiré une partie de la classe moyenne travaillant dans la ville voisine de Nijmegen, à la recherche d'un contact plus étroit avec "la campagne" et "la nature". À partir d'une brève étude sur le terrain, j'analyse certains conflits sociaux présents, fondés essentiellement sur une critique du concept de communauté et sur les oppositions entre les plans rural et urbain, tout en discutant les sens que de telles notions acquièrent dans ce cas précis. 